\title{
THE GAINS FROM PREFERENTIAL TAX REGIMES RECONSIDERED
}

\author{
Carl Gaigné ${ }^{\Upsilon}$
}

INRA, UR122, Rennes (France)

\author{
Ian Wooton \\ University of Strathclyde, Glasgow (UK) \\ CEPR and CESifo
}

\begin{abstract}
The EU policy against harmful tax competition aims at eliminating tax policies targeted at attracting the internationally mobile tax base. We construct an imperfectly competitive model of costly trade between two countries. In setting their corporate taxes, governments non-cooperatively decide whether to discriminate between internationally mobile and immobile firms. We find the Nash equilibrium tax regimes. When trade costs are high countries impose a uniform tax on all firms while nations will discriminate between mobile and immobile firms when costs are low. At some trade costs, fiscal competition results in tax discrimination despite uniform taxation being socially preferable.
\end{abstract}

Key words: preferential tax regimes; tax competition; imperfect competition, trade costs

JEL Classification: H87, F12

\footnotetext{
${ }^{\Upsilon}$ Corresponding author: Carl Gaigné, INRA, UR122, Economie Rurale, 4 allée Bobierre, F-35000 Rennes (France). Email : gaigne@rennes.inra.fr.

We are grateful to two anonymous referees for their criticism and suggestions. We would also like to thank participants in seminars at ETH Zurich, Hitotsubashi University, and the Asia-Pacific Trade Seminar in Osaka for their comments..
} 


\section{INTRODUCTION}

The process of economic integration among major industrialised countries and the increasing mobility of capital have recently raised the question of the desirability of preferential tax regimes. Indeed, some national governments have adopted tax policies that discriminate across sectors according to the degree of international mobility of firms. Such strategies may allow countries to maximise their tax revenues from operations that cannot escape to other tax jurisdictions while offering more competitive tax rates in order to attract (or retain) more "footloose" activities. Ireland is a well-known example. This country levied a $10 \%$ tax rate on corporate income in the manufacturing and financial services sectors compared to $24 \%$ in other sectors. This measure was largely to encourage investment by multinational firms, major players in these two sectors. The OECD (1998) and the European Union (European Commission, 1997) have argued that giving preferential tax treatment to non-residents, or to activities that do not impinge on domestic markets, constitutes a harmful tax regime. The OECD (2004) identified 47 preferential tax regimes within OECD member states in 2000. OECD (2010) reports that all but one of these regimes has been abolished, amended or found not to be harmful, with the remaining regime due to be abolished by the end of $2010 .{ }^{1}$

It is, however, less than obvious that shifting to a non-discriminatory corporate tax policy would be beneficial. Indeed, a transition from a preferential regime to a uniform tax policy would seem to result in lower taxes on the relatively immobile base with an increase in taxes on the more mobile base. In other words, the negative effects of tax competition are spread over the entire tax base, as opposed to the fraction of the base that is internationally mobile. Consequently, a uniform tax policy enables governments to raise revenues from more mobile tax bases while revenues from more immobile bases increase when preferential regimes are applied.

This explains why the academic literature does not deliver a clear message on the efficiency of tax discrimination. For example, according to Janeba and Peters (1999), a uniform tax regime is preferred to tax discrimination because this tax regime allows governments to exploit the mobile tax

\footnotetext{
${ }^{1}$ In addition, many European countries have recently increased the sophistication of their policies to attract foreign firms. According to Charlton (2003), all the major western European nations offer grants or tax
} 
base. On the other hand, according to Keen (2001, p 762), "preferential regimes may serve a useful purpose in limiting the scope of tax competition".

Clearly, the relative merits of a regime based on tax discrimination depend crucially on the assumptions that are made. In Janeba and Peters (1999), one of the tax bases is perfectly mobile with respect to differences in taxation while the other is completely immobile. In addition, they assume that the size of tax bases depends on the level of tax rates. Keen's (2001) approach is based on two mobile tax bases which differ in their degrees of international mobility and on the assumption of an aggregate tax base that is fixed. Janeba and Smart (2003) reconcile the apparently conflicting results of Janeba and Peters (1999) and Keen (2001). The desirability of tax discrimination depends on the elasticities of the aggregate bases according to Janeba and Smart (2003). The authors provide a general condition which encompasses the conditions provided by Janeba and Peters (1999) and Keen (2001). Tax discrimination is preferable when aggregate base elasticities are sufficiently low. In addition, when the tax base with the higher tax rate in the absence of restrictions on tax preferences is the less internationally mobile, differences in tax rates lead to a fall in tax revenues. In the extreme case, where one base is perfectly immobile as in Janeba and Peters (1999), a uniform tax policy in each country is required. $^{2}$

All of these previous contributions assume that the degree to which a given tax base is internationally mobile is exogenously given and that all mobile factors locate in the country with the lower taxation. However, decisions on the location of production are not simply driven by tax factors but by other economic considerations such as increasing returns, trade costs, and market structure (Head and Mayer, 2004).

In this paper, we assume that the market is characterized by imperfect competition and increasing returns to scale and that trade between countries is costly, as in models of economic

incentives to attract foreign firms. Charlton (2003) lists different cases where investment subsidies are substantial, accounting for $10-30 \%$ of the value of the investment.

${ }^{2}$ A similar result is also obtained by Haupt and Peters (2005) who extended Keen's approach by assuming that tax bases have regional preferences. This home bias reflects the fact that investment abroad involves higher information, monitoring, and transaction costs and implies greater uncertainty than investments at home. Haupt and Peters (2005) conclude that preferential regimes may make tax competition more harmful, even if the aggregate tax bases are exogenously fixed. Recall that, in Keen (2001), a transition from a preferential regime to a uniform tax policy implies a lower tax on the relatively immobile base to which fierce inter-jurisdictional competition is redirected. This negative impact is mitigated by the existence of a home bias. 
geography with tax competition (Andersson and Forslid, 2003; Baldwin and Krugman, 2004; Kind et al., 2000; Ludema and Wooton, 2000; Ottaviano and van Ypersele, 2005). In our model, the stock of capital is split in two: one part that is fixed in its location, unable to respond to international differences in rates of return, and one that is internationally mobile, for which the location choice is endogenous. ${ }^{3}$ As a result, the mobile tax base's response to the international difference in tax rates will depend upon market conditions in the economy, such as trade costs and the share of mobile firms. This raises the question whether this competition for mobile firms in the presence of imperfectly competitive markets and trade costs makes tax discrimination wasteful.

In contrast to other models of trade and location with tax competition, we use a game-theoretic approach where the governments non-cooperatively choose their tax regimes (discrimination or uniform) prior to setting their tax rates. In contrast to Janeba and Peters (1999), we consider a third stage in which each mobile firm chooses its location, taking as given the governments' tax policies. We show that trade integration favours the implementation of discriminatory tax regimes because of the high elasticity of the mobile tax-base when trade costs are low. In addition, uniform tax policies are more likely to emerge when internationally mobile firms account for a large share of the firms in the economy. In this situation, mobile firms are less inclined to agglomerate in the country with the lower tax rate because price competition among firms would be very fierce. We further find that, in some equilibria where tax discrimination is adopted, this tax regime yields lower welfare compared to one where the governments had set uniform taxes.

In section 2, the structure of the 2-country, 2-sector model of production and consumption in presented. Section 3 examines the spatial allocation of mobile firms and equilibrium choices of tax rates, given the tax regime, while the choice of tax regime itself is analysed in section 4 . In the last section, we conclude.

\footnotetext{
${ }^{3}$ Ludema and Wooton (1999) use a variant of Krugman's (1991) model of economic geography in order analyse the effects of differences amongst workers with regard to their willingness to move between international markets. They do not, however, consider tax policy.
} 


\section{THE MODEL}

We consider a regional economy with two countries, labelled $a$ and $b$, that compete for the investment of foreign-owned firms in a modern sector. These firms produce a homogeneous good, $x$, in an oligopolistic industry. In addition, a traditional sector produces good $z$ under perfect competition. ${ }^{4}$

The two countries are identical and there are $n$ workers in each. The residents of countries $a$ and $b$ earn only wage income, while (after-tax) profit income in the modern sector accrues to capital owners that reside in a third (outside) country. Every household in the region supplies a single unit of labour. The wage rate in each country is determined in the traditional, numeraire industry, which uses labour as the only input and is assumed to be always active in both countries. Free trade in the numeraire good therefore equalises the wage across the countries as $w$.

\subsection{Consumers}

Consumers in both countries have identical preferences for the goods, given by

$$
u_{i}=\alpha x_{i}-\frac{\beta}{2} x_{i}^{2}+z_{i}, \quad i \in\{a, b\} .
$$

The budget constraint for a representative consumer in country $i$ is

$$
w=z_{i}+p_{i} x_{i}, \quad i \in\{a, b\} .
$$

where $p_{i}$ is the price of good $x$ in country $i$. Utility maximisation yields inverse demand curves

$$
\alpha-\beta x_{i}=p_{i}, \quad i \in\{a, b\} .
$$

Aggregating over the $n$ consumers in each country yields market demand curves

$$
X_{i}=\frac{n\left(\alpha-p_{i}\right)}{\beta}, \quad i \in\{a, b\} .
$$

\subsection{Firms}

We assume that there are $k$ firms in the modern sector, each based in a third country and prepared to invest in the region. ${ }^{5}$ Each firm possesses one unit of "knowledge capital" (such as a license or

\footnotetext{
${ }^{4}$ Our modelling approach is closely related to that of Haufler and Wooton (2010) whose interest is in the number and spatial allocation of modern firms in an asymmetric region as trade barriers are lowered, whereas our interest lies in the tax regime choices made by identical countries. A Cournot oligopoly structure provides similar, but slightly more tractable, results to those from monopolistic competition framework, such as Ottaviano and van Ypersele (2005) or Gaigné and Riou (2007).
} 
franchise to produce) that can be profitably employed in the imperfectly competitive industry $x$. This factor is indispensable for the production of good $x$ but limited in availability such that only $k$ firms can engage in production. Each firm sets up a single production plant in the region and serves the regional market from either country $a$ or country $b .^{6}$

The modern firms are assumed to be identical with respect to their technology. We assume, however, that some firms are internationally mobile while the remainder are locked into producing in a particular country. This assumption captures the fact that some agents choose to invest in their home country even if this domestic investment is subject to a higher taxation and results in lower after-tax profits than an overseas investment. ${ }^{7}$ Location matters because, while all firms can sell their products in both countries, there are trade costs associated with exports to a firm's foreign market. Thus each country's market may be served by both "local" firms that produce domestically and "foreign" firms that are based in the other country.

Labour is the only variable input in good $x$ production. Each unit of good $x$ requires the efforts of a single worker and hence the marginal cost of production is $w$. Since wage costs are equalised between the two countries, they do not enter the location decision of firms in our model. The cost of exporting each unit of output is $\tau$, which effectively raises the marginal cost of serving the foreign market to $(w+\tau)$. We are assuming that all of the trade costs are "real", taking the form of, say, transport costs, administrative barriers to the free movement of goods between countries or specific tariffs. There are no (endogenously determined) $a d$ valorem tariffs between countries $a$ and $b{ }^{8}$

Firms are assumed to behave as Cournot competitors and are able to segment their markets, choosing the quantities to sell on their domestic and export markets independently. The total operating profit of each firm, which equals the return to the required unit of knowledge capital, is thus defined as

\footnotetext{
${ }^{5}$ We rule out the possibility of domestic ownership of some share of the firms in the modern sector. This is in order to simplify the analysis, otherwise we would have to keep track of the firm ownership and deduct tax revenues from domestic shareholders from our objective function.

${ }^{6}$ Each licence holder is assumed to be limited to establishing a single production facility.

${ }^{7}$ This may be explained by some home-bias in the preferences of investors, perhaps arising from fear of an unknown foreign investment climate, or some form of physical fixity with respect to some of the capital stock.

${ }^{8} \mathrm{We}$ model the trade cost as a financial cost to the firms, fixed in terms of the numeraire good. An alternative approach would be to use "iceberg" trade costs. The qualitative results of the analysis are the same in both cases.
} 


$$
\begin{aligned}
& \pi_{a}=\left(p_{a}-w\right) x_{a a}+\left(p_{b}-w-\tau\right) x_{b a}, \\
& \pi_{b}=\left(p_{a}-w-\tau\right) x_{a b}+\left(p_{b}-w\right) x_{b b},
\end{aligned}
$$

where $\pi_{j}$ is the pre-tax profit of a firm based in country $j$ and $x_{i j}$ represents sales in country $i$ by a firm based in country $j(i, j \in\{a, b\})$. As a firm is at a cost disadvantage in its export market due to the marginal cost of servicing foreign consumers, an exporter will sell less in a market than an indigenous rival.

We assume that, of the $k$ firms operating in the modern sector, a proportion $m$ are internationally mobile while the remainder are unable to move between countries in response to differences in after-tax profits. The immobile firms are assumed to be evenly split between countries $a$ and $b$, while a proportion $\delta$ of the "footloose" firms operates in country $a$. The number of modern firms operating in countries $a$ and $b$ is $k \sigma$ and $(1-\sigma) k$, respectively, where

$$
\sigma \equiv \frac{1}{2}+\left(\delta-\frac{1}{2}\right) m
$$

If $m=1$, all firms are footloose and $\sigma=\delta$ while if $m=0$, all firms are immobile and evenly split between to two host nations, $\sigma=1 / 2$. All firms service both their domestic and foreign markets, so the total supply to each market is ${ }^{9}$

$$
\begin{aligned}
& X_{a}=k \sigma x_{a a}+k(1-\sigma) x_{a b}, \\
& X_{b}=k(1-\sigma) x_{b b}+k \sigma x_{b a} .
\end{aligned}
$$

Profit maximisation, using (3), (4) and (6), yields the optimal output levels of firms in each market together with national outputs and prices for the modern sector:

\footnotetext{
${ }^{9}$ Our trade structure is a generalisation of the Brander and Krugman (1983) "reciprocal dumping" model from duopoly to $k$-good oligopoly. In order for trade to occur, the trade costs cannot be too high. Prohibitive trade costs for country $a$ are $\tau_{a}{ }^{p} \equiv(\alpha-w) /(\sigma k+1)$. A similar expression holds for country $b$.
} 


$$
\begin{array}{ll}
x_{a a}=\frac{n[\alpha-w+k(1-\sigma) \tau]}{\beta(k+1)} ; & x_{b a}=\frac{n[\alpha-w-(1+k(1-\sigma)) \tau]}{\beta(k+1)} ; \\
x_{a b}=\frac{n[\alpha-w-(1+k \sigma) \tau]}{\beta(k+1)} ; & x_{b b}=\frac{n[\alpha-w+k \sigma \tau]}{\beta(k+1)} ; \\
X_{a}=\frac{n k[\alpha-w-(1-\sigma) \tau]}{\beta(k+1)} ; & X_{b}=\frac{n k[\alpha-w-\sigma \tau]}{\beta(k+1)} ; \\
p_{a}=\frac{\alpha+k w+k(1-\sigma) \tau}{k+1} ; & p_{b}=\frac{\alpha+k w+k \sigma \tau}{k+1} .
\end{array}
$$

From (7), we can determine the total profits for firms based in each country

$$
\begin{aligned}
& \pi_{a}=\frac{n[\alpha-w+k(1-\sigma) \tau]^{2}}{\beta(k+1)^{2}}+\frac{n[\alpha-w+(1+k(1-\sigma)) \tau]^{2}}{\beta(k+1)^{2}}, \\
& \pi_{b}=\frac{n[\alpha-w-(1+k \sigma) \tau]^{2}}{\beta(k+1)^{2}}+\frac{n[\alpha-w+k \sigma \tau]^{2}}{\beta(k+1)^{2}} .
\end{aligned}
$$

The spatial allocation of firms affects their profitability in each market. The marginal cost of servicing local consumers is less and, hence, generally more profitable than exporting. However, the greater the concentration of mobile firms in a particular location, the more competitive that environment becomes and, consequently, the less profitable. Comparing pre-tax profits of mobile firms in (8) yields

$$
\pi_{a}-\pi_{b}=2 \mu(1-2 \sigma) \tau^{2}
$$

where we define $\mu \equiv n k / \beta(k+1)$. If $\sigma>1 / 2$, more firms are based in country $a$ and, consequently, they have relatively lower profits than those in country $b$ due to the more intense competition.

\subsection{Governments}

We assume that the single objective of each nation's government is the maximisation of corporate tax revenue by the imposition of lump-sum taxes on firms located within their jurisdictions. ${ }^{10}$ The literature on tax competition for foreign direct investment often considers additional policy goals, such as the increased consumer surplus arising from local production, additional employment of domestic

\footnotetext{
${ }^{10}$ This assumption permits a comparison of our results with the existing literature on whether tax discrimination is desirable (see Janeba and Peters, 1999; Keen, 2001; Haupt and Peters, 2005).
} 
workers, and the possibility technological spillovers from the foreign firms to indigenous industry. ${ }^{11}$ In all such cases, national welfare increases with the number of firms that are attracted to a country. That is not necessarily the case when tax revenues are the objective, as both the tax base (directly related to the number of firms producing in the country) and the rate of tax that is charged on firms will matter, such that having fewer, more highly taxed firms might be a better outcome to a nation. Because of this, we have restricted our set of objectives to total corporate tax revenues.

The taxable base and the rate of tax that is charged are closely related, in that firms will attempt to avoid taxes and, to the degree that they can move out of a tax jurisdiction, will respond to high taxes my moving to nations with lower tax rates. This is an issue in our model with respect to the footloose firms. High tax rates that result in relatively low after-tax profits in a host country will result in flight to the other jurisdiction. The immobile firms, in contrast, are unable to avoid high rates of tax and can merely adjust their output to maximise their after-tax profits.

The government of each country has a choice of tax regime. The first option is to treat all of the firms that a country hosts in a uniform fashion by charging a common corporate tax on modern firms, regardless of their degree of mobility. The alternative is to discriminate between firms based upon their ease of international movement and to set a different (presumably lower) corporate tax on the footloose firms. The relative attractiveness of the policies is likely to depend upon the policy choice made by the other nation.

Having chosen its tax policy, a government must decide upon the tax that it will charge modern firms. This decision must, again, be made in the context of the competition with the other country to attract (and derive tax revenues from) the mobile firms.

\subsection{Sequence of events}

In the first stage of a three-stage game with complete information, the two governments simultaneously choose their tax regimes, deciding whether to discriminate between mobile and immobile firms in tax rates or to set a uniform corporate tax. ${ }^{12}$ In the second stage, the governments

\footnotetext{
${ }^{11}$ These alternative objectives are addressed elsewhere in the literature (see, for example, Haufler and Wooton, 2010).

${ }^{12}$ Introduction of ad valorem corporate taxes would complicate the algebra but would not change our qualitative results.
} 
simultaneously set the taxes on profits, taking as given the tax decisions of the other government and anticipating the private sector outcomes and the resulting location equilibrium. In stage 3 , following the tax policy announcements of the two governments, firms choose the location of their production. We wish to find the subgame-perfect Nash equilibrium using backward induction, beginning with the last stage. ${ }^{13}$

\section{TAX POLICY AND LOCATION}

\subsection{The spatial allocation of mobile firms}

The location choice of mobile firms depends upon the international difference in net-of-tax profits. A spatial equilibrium is such that, in each country, no mobile firm has an incentive to change location. Let the tax differential facing mobile firms be $\Delta \equiv t_{a}-t_{b}$. Then an interior spatial equilibrium (that is, one where mobile firms are located in both countries) occurs when

$$
\pi_{a}-\pi_{b}=\Delta .
$$

An interior equilibrium is stable if and only if the slope of the profit differential is negative in the neighbourhood of the equilibrium, whereas agglomerated equilibria ( $\delta=0$ or 1$)$ are always stable whenever they exist. The derivative of (9) with respect to the share of firms in country $a$ is negative, confirming that an interior equilibrium is stable. ${ }^{14}$

By substituting (9) into(10), we find the equilibrium share of mobile firms $(\delta)$ that locates in country $a$ :

$$
\delta=\frac{1}{2}\left(1-\frac{\Delta}{2 m \mu \tau^{2}}\right) .
$$

\footnotetext{
${ }^{13}$ This will ensure that the governments' choices of tax regimes are credible and that there will be no incentive for either government to change its announced regime.

${ }^{14}$ In order for an agglomerated equilibrium to arise in our model (and, indeed, in any economic geography framework), there needs to be some force that attracts mobile factors to the core and away from the periphery. Haufler and Wooton (2010) simply assume that the market in one country is larger than the other, making it more attractive to firms. In Krugman (1991) the outcome is endogenous. With differentiated products, mobile factors are attracted to the core, due to its lower average prices, while firms are driven to the periphery by the more intense competition in the larger market. The agglomerative force of Krugman (1991) is absent from our (symmetric) model as the manufactured good is homogeneous, ensuring that the only equilibria are dispersed.
} 
Equation (11) shows that, ceteris paribus, mobile firms will be inclined to concentrate in the low-tax country. However, spatial dispersion of mobile firms is encouraged both by high trade costs and by there being a large share of mobile firms in industry.

Define $\varepsilon_{i}$ to be the elasticity of the mobile tax base in country $i$ with respect to its own corporate tax rate $t_{i}$ :

$$
\varepsilon_{i} \equiv \frac{d \delta}{d t_{i}}\left(\frac{t_{i}}{\delta}\right)=\frac{-t_{i}}{2 m \mu \tau^{2}-\left(t_{i}-t_{j}\right)},
$$

where $\varepsilon_{i}<0$ for $0<\delta<1$. Contrary to the standard literature on the desirability of preferential taxation regimes, our tax-base elasticity varies with respect to the parameters of the economy. The response of mobile firms to tax differences becomes less elastic when a larger share of the firms are able to move $\left(d\left|\varepsilon_{i}\right| / d m<0\right)$ and when trade costs are high $\left(d\left|\varepsilon_{i}\right| / d \tau<0\right)$. The latter effect can be explained by the fact that high trade costs insulate a domestic market from foreign competition, such that a firm will be more reluctant to leave a country despite its relatively high tax level, as it wishes to avoid the more competitive environment of the other country. In contrast, low trade costs provide no such home-market advantage and will result in footloose firms being relatively more responsive to corporate tax differences.

\subsection{Equilibrium tax policies}

We denote the tax-policy configuration for countries $i$ and $j$ as $C$ where $C \in\{U U, D D, U D, D U\}$ :

$U U$ : both countries adopt a uniform tax policy;

$D D$ : both countries apply a discriminatory tax policy, setting different taxes on mobile and immobile firms;

$U D$ : country $i$ applies a uniform tax policy while country $j$ has a discriminatory tax regime;

$D U$ : country $i$ has a discriminatory tax regime while country $j$ applies a uniform tax policy.

The objectives of the revenue-maximising governments can be represented as follows:

$$
R_{a}^{C}=\operatorname{Max}_{t_{a}, r_{a}}\left[t_{a} \delta m+r_{a} \frac{(1-m)}{2}\right] k, \quad R_{b}^{C}=\underset{t_{b}, r_{b}}{\operatorname{Max}}\left[t_{b}(1-\delta) m+r_{b} \frac{(1-m)}{2}\right] k,
$$


where $t_{i}$ is the tax rate on mobile firms based in country $i$ and $r_{i}$ is the tax rate on immobile firms. In configurations $U U$ and $U D$, when a uniform tax policy is adopted by country $i$, then $t_{i}=r_{i}$. However, when the government chooses to discriminate between mobile and immobile firms, these tax rates can differ.

We can investigate revenues captured by countries in each policy configuration.

\subsubsection{UU, uniform taxes in both countries}

Given that all firms located in a country face the same tax, we simplify (12) to:

$$
R_{a}^{U}=\operatorname{Max}_{t_{a}}\left[t_{a} \sigma\right] k, \quad R_{b}^{U}=\underset{t_{b}}{\operatorname{Max}}\left[t_{b}(1-\sigma)\right] k,
$$

where country $a$ 's share of firms $\sigma$ was defined in (5), while its equilibrium value is determined by the international tax differential. By plugging (5) and (11) into (13), we obtain tax revenues as functions of national taxes:

$$
R_{a}^{U}=\frac{t_{a}\left[2 n k \tau^{2}-\beta(k+1)\left(t_{a}-t_{b}\right)\right]}{4 n \tau^{2}}, \quad R_{b}^{U}=\frac{t_{b}\left[2 n k \tau^{2}+\beta(k+1)\left(t_{a}-t_{b}\right)\right]}{4 n \tau^{2}} .
$$

Differentiating the expressions in (14) with respect to the national tax rates, substituting for $\mu$ and solving, yields a country's best response function:

$$
t_{i}^{U}\left(t_{j}\right)=\mu \tau^{2}+\frac{t_{j}}{2}, \quad i, j \in\{a, b\}, i \neq j
$$

The common, Nash equilibrium tax on firms can be found from (15) as

$$
t^{U U}=2 \mu \tau^{2}
$$

As taxes are the same, each nation attracts half of the mobile firms and hence $\sigma=\delta=1 / 2$. The tax revenues collected by each country in this symmetric equilibrium will also be the same:

$$
R^{U U}=k \mu \tau^{2}
$$

The equilibrium tax in (16) reflects what Haufler and Wooton (2010) refer to as a locationrent effect. National governments are able to tax mobile firms, capturing the differential between profits accruing to a firm in its present location and those that would arise should it move to the other 
country. ${ }^{15}$ As discussed in section 3.1 , the higher the trade barrier $\tau$, the less elastic the mobile tax base and hence the stronger this effect. If trade were entirely free $(\tau=0)$, governments would have no ability to tax in a classic, "race to the bottom" scenario of tax competition for mobile factors.

\subsubsection{DD, tax discrimination in both countries}

In this setting, each government maximises its tax revenue from the mobile firms operating within its borders while extracting the maximum rents from the immobile capital. As immobile firms have no choice but to produce in the country in which they are located, they will be prepared to operate as long as they can make non-negative profits. Given that governments maximise tax revenues, they set the tax on immobile firms so as to extract all of their profits. Thus, the corporate tax $r_{i}$ on an immobile firm located in country $i$ will be set equal to its pre-tax profit $\pi_{i}$ in (8).

While a government is able to grab all of the profits of its immobile firms, these earnings are to some degree determined by the spatial distribution of the mobile firms from within the same industry. Indeed, of the more mobile firms that produce locally, the lower the profits of (and hence the tax on) immobile firms due to fiercer price competition. The tax rate on immobile firms is then:

$$
\begin{gathered}
\qquad r_{i}=F+\frac{\left(t_{i}-t_{j}\right)}{2}\left[\frac{\beta\left(t_{i}-t_{j}\right)}{4 n \tau^{2}}+1\right], \quad i, j \in\{a, b\}, i \neq j, \\
\text { where } F \equiv \frac{\mu}{2 k(k+1)}\left[4(\alpha-w)(\alpha-w-\tau)+\left(k^{2}+2 k+2\right) \tau^{2}\right] .
\end{gathered}
$$

$F$ is the component of the tax that is independent of the location of mobile firms. It is clear from the other component of (18) that if a country has a relatively higher tax than its rival, it will chase away some of the footloose firms and thereby be able to extract greater tax revenues from its increasingly profitable, immobile firms. As a result, the tax rates on mobile and immobile firms within each country are positively correlated and, in setting its tax on mobile capital, a government must take account of the impact on revenues from immobile firms.

Tax revenues from a discriminatory tax policy are:

\footnotetext{
${ }^{15}$ In the symmetric equilibrium, profits are the same in both countries. Should one firm move, it will increase competition in its new location and lower profits, while raising the profitability of those firms that it left behind.
} 


$$
R_{a}^{D}=k\left[t_{a} \delta m+r_{a} \frac{(1-m)}{2}\right], \quad R_{b}^{D}=k\left[t_{b}(1-\delta) m+r_{b} \frac{(1-m)}{2}\right],
$$

where $r_{i}$ is determined in (18) and $\delta$ is found from (11) and both depend upon the tax rates on mobile firms that are set by both governments.

Differentiating the expressions in (19) with respect to the national tax rates and solving, yields a country's best response function:

$$
t_{i}^{D}\left(t_{j}\right)=\frac{(1+m) k+2}{(3+m) k+4} t_{j}+\frac{2 n(1+m) k \tau^{2}}{\beta[(3+m) k+4]}, \quad i, j \in\{a, b\}, i \neq j .
$$

The common, Nash equilibrium tax on firms can be found from (20) as

$$
t^{D D}=(1+m) \mu \tau^{2}
$$

Both the share of mobile firms in the economy and level of trade costs have a positive influence on tax rates under tax discrimination, because they make the tax-base less elastic. Comparing (21) to (16), it is clear that the equilibrium tax on mobile firms in a discriminatory tax regime is always less than that on mobile firms (and all other firms) in a uniform tax regime. As expected, tax competition to attract mobile tax base is fiercer under the former regime than under the latter regime.

As the tax on mobile firms is the same in both countries, each nation will attract half of the mobile firms and hence $\sigma=\delta=1 / 2$. Substituting this into (18), we find that both countries impose the same tax on their immobile firms, $r^{D D}=F .^{16}$ The tax revenues collected by each country in this symmetric equilibrium will also be the same:

$$
R^{D D}=\frac{k}{2}\left[m(1+m) \mu \tau^{2}+(1-m) F\right]
$$

The difference in tax revenues accruing to a host country when both nations discriminate as opposed to both setting uniform taxes can be seen from a comparison of (22) and (17). If all firms are footloose $(m=1)$, the two expressions coincide, as there is no immobile capital to treat differentially. As the proportion of footloose firms declines $(m<1)$, a gap develops between the expressions because discriminatory governments are able to grab all of the immobile firms' profits. We shall return to this

\footnotetext{
${ }^{16} \mathrm{We}$ assume that market size $(\alpha)$ is sufficiently large to ensure positive after-tax profits for mobile firms or, equivalently, $F \geq t^{U U}$.
} 
comparison later, when we consider the Pareto optimality of the Nash equilibrium from the regime game.

\subsubsection{UD and $D U$, mixed regimes}

The determination of the optimal tax levels in a mixed regime, where one country discriminates between mobile and immobile firms while the other country sets a uniform tax, merely combines the best-response functions of the other tax-setting regimes.

Suppose that each country were to adopt a different tax policy, so that the best tax for one country is determined by (15) while the other country's rest-response to its rival's tax is given by (20). The resulting Nash equilibrium tax rates are:

$$
t^{U D}=2 \mu \tau^{2} \frac{(4+2 m) k+(5+m)}{(5+m) k+6} \quad \text { and } \quad t^{D U}=2 \mu \tau^{2} \frac{(3+3 m) k+(4+2 m)}{(5+m) k+6},
$$

with

$$
\Delta^{U D} \equiv t^{U D}-t^{D U}=2 \mu \tau^{2} \frac{(1-m)(k+1)}{(5+m) k+6]}>0 .
$$

Clearly, whenever some firms are internationally immobile $(m<1)$, the tax set on mobile firms by the country with a uniform tax policy exceeds that of the discriminatory government. In other words, the country applying discriminatory taxes attracts the majority of the mobile firms.

We can compare the tax rates on mobile firms applied in each tax-policy configuration. From (16), (21), and (23), we find that:

$$
t^{U U}>t^{U D}>t^{D U}>t^{D D}>0 .
$$

This is shown diagrammatically in Figure $1 .{ }^{17}$ It is the case that equilibrium tax rates decline with trade integration, regardless of the type of tax regime adopted in both countries. Such a result is in accordance with the empirical literature showing that nominal and effective average rates of corporation tax have fallen over the last two decades in OECD countries (Devereux et al., 2002).

\section{INSERT FIGURE 1 NEAR HERE.}

\footnotetext{
${ }^{17}$ Figures 1 and 2 are derived from numerical simulations with parameter values: $\alpha=5, \beta=1, w=1, n=10$, $k=10$, and $m=0.3$. None of the qualitative results, except where explicitly identified, is affected by this choice of parameters.
} 
We can also compare the tax rates on immobile firms applied in each tax regime. The country that adopts a uniform regime, by definition, charges the same tax on its mobile and immobile firms. It also, from (24), sets a higher tax on mobile firms and consequently attracts a smaller share of these companies. The discriminatory country therefore attracts more than half of the mobile firms, making its market more competitive than when both countries discriminate between mobile and immobile firms. Taking this into account, and using (18), the tax rates applied on immobile firms by a discriminatory country under a mixed configuration is $r^{D U}<F=r^{D D}$.

The tax revenues that arise from a mixed regime can be determined by substituting (23) into (14) and (19):

$$
\begin{aligned}
& R^{U D}=\frac{k}{2}\left[m(1+m)+(1-m) \theta_{L}\right] \mu \tau^{2}, \\
& R^{D U}=\frac{k}{2}\left[\left(2-(1-m) \theta_{H}\right) \mu \tau^{2}+(1-m) F\right],
\end{aligned}
$$

where we have defined threshold parameters:

$$
\begin{aligned}
& \theta_{L} \equiv \frac{2\left[k^{2} m^{2}+\left(7 k^{2}+8 k-1\right) m+(4 k+5)^{2}\right]}{[(5+m) k+6]^{2}}+m, \\
& \theta_{H} \equiv \frac{\left[\left(11 k^{2}+7 k\right) m^{2}+\left(58 k^{2}+94 k+28\right) m+99 k^{2}+235 k+140\right]}{2[(5+m) k+6]^{2}} \\
& \theta_{H}>\theta_{L}, \quad \frac{d \theta_{L}}{d m}>0, \quad \text { and } \quad \frac{d \theta_{H}}{d m}>0 .
\end{aligned}
$$

There is no immediate intuition to the above expressions. Notice that as $m \rightarrow 1$, and all firms become internationally mobile, all of the expressions for tax revenue converge. When only some firms are footloose, the revenues under each regime pull apart bringing different levels of benefit to the countries. We shall examine these differences in Stage 1 of the game to determine the governments' optimal choices of regime. 


\section{THE CHOICE OF TAX REGIME}

\subsection{Tax discrimination versus a uniform tax}

We know the tax revenues of each country under the configurations of tax regime ( $U U, D D, U D$ and $D U$ ) and these are presented in Table 1. In order to make comparisons more straightforward, we substitute $\varphi$ into our revenue expressions (17),(22), (25) and (26) where we define

$$
\varphi \equiv \frac{F}{\mu \tau^{2}}, \quad \text { where } \quad \frac{d \varphi}{d \tau}<0
$$

It is also useful to define an additional threshold parameter $\theta_{S}$ where

$$
\theta_{S} \equiv m+2 \text { and } \theta_{S}>\theta_{H} \text {, }
$$

such that $R^{D D}=R^{U U}$ when $\varphi=\theta_{S}$.

\section{INSERT TABLE 1 NEAR HERE.}

We are interested in determining the economic conditions under which a particular policy regime constitutes a sub-game perfect Nash equilibrium. The payoffs in Table 1 reveal that outcome $D D$, where both countries apply tax discrimination, is stable if and only if $\varphi>\theta_{L}$. In contrast, the outcome when both countries adopt a uniform tax policy is stable if and only if $\varphi<\theta_{H}$. We now investigate the possible equilibria in more detail. Figure 2 provides an illustration of our results.

\section{INSERT FIGURE 2 NEAR HERE.}

Consider the situation where trade costs are negligible, that is $\tau$ is close to zero so that $\varphi>\theta_{H}>\theta_{L}$. In this situation, there is a race to the bottom in the pursuit of investment from footloose firms, driving down tax revenues from mobile firms. Indeed, the mobile tax-base elasticity is very high when trade costs are close to zero so that each government is prompted to apply a discriminatory tax policy. Consequently, the only source of tax revenues will be from those firms that cannot move. Regardless of the regime choice of its rival, each government's dominant strategy will be to treat the two types of firms differently, as both $R^{D D}>R^{U D}$ and $R^{D U}>R^{U U}$. Thus $D D$ is the unique Nash equilibrium.

As trade costs increase, the tax revenues that can be collected from mobile firms rise and, consequently the relative attractiveness of a uniform tax regime increases. As trade costs rise above a threshold level $\tau_{1}$ (implicitly defined by $\varphi=\theta_{S}$ ) the tax revenues that would arise from both countries 
switching to a uniform tax regime become greater than those collected from the discriminatory tax regime that remains the unique Nash equilibrium. Thus a prisoner's dilemma has arisen at these trade costs. Both countries would benefit from a change of tax regime but neither will make that adjustment as discrimination between types of firms remains the dominant strategy.

As trade costs increase further to cross the threshold level $\tau_{2}$ (implicitly defined by $\varphi=\theta_{H}$ ), the rankings of revenues under different policy configurations change, such that we now have $R^{U U}<R^{D U}$ while it remains the case that $R^{D D}>R^{U D}$. In this situation, the mobile tax-base elasticity takes intermediate values. As a result, two Nash equilibria ( $D D$ and $U U$ ) now exist where countries adopt the same tax-policy regime. It is the case that, as trade costs are above $\tau_{1}, U U$ is Pareto superior to $D D$.

Further increases in trade costs, crossing a threshold $\tau_{3}$ (implicitly defined by $\varphi=\theta_{L}$ ), reverse the remaining inequality such that $R^{U D}>R^{D D}$ and adopting a uniform tax policy becomes the dominant strategy of each country. ${ }^{18}$ Indeed, the elasticity of the mobile tax-base has fallen sufficiently that, if one country were to adopt a uniform tax policy while the other country applied tax discrimination, the uniform tax rate in the former country would exceed those on both the immobile and mobile firms in the latter $\left(t^{U D}>r^{D U}, t^{D U}\right)$ and relatively few firms would migrate to the lower-tax country. Consequently there is a unique Nash equilibrium of $U U$ in which both countries treat all of their firms uniformly.

This result can be summarised in the following proposition.

Proposition 1. The equilibrium choice of tax regimes depends upon the level of trade costs between nations. When barriers to trade are sufficiently high $\left(\tau>\tau_{3}\right)$, the equilibrium is unique, with governments imposing the same taxes on all firms. As trade costs decline $\left(\tau_{3}>\tau>\tau_{2}\right)$, a second Nash equilibrium arises where both nations discriminate between mobile and immobile firms. Continuing trade integration eventually $\left(\tau_{2}>\tau\right)$ leads to discrimination becoming the sole equilibrium tax regime.

Four zones are indicated in Figure 2 which illustrates the relationship between a nation's corporate tax revenues and the level of trade costs between markets. The upper limit to zone 4 is the

\footnotetext{
${ }^{18}$ We can show that this outcome can arise at high, yet not prohibitive, trade costs.
} 
prohibitive trade cost beyond which the countries do not trade with each other. Within zone 4, a uniform tax regime returns the highest revenues, regardless of the other nation's tax policy. Consequently the unique Nash equilibrium is $U U$. Below $\tau_{3}$, in zone 3 , a country's best response to its rival setting discriminatory taxes is to adopt the same policy and consequently two Nash equilibria coexist ( $U U$ and $D D$ ). Continuing trade integration below $\tau_{2}$ results in tax discrimination being the best response to either tax regime of its rival and thus $D D$ is the unique Nash equilibrium in zones 1 and 2 .

It should be also noted that the share of mobile firms in the economy affects the choice of tax regime. As both $\theta_{L}$ and $\theta_{H}$ increase with $m$, a higher proportion of mobile firms favours the implementation of uniform tax regime as the tax-base becomes less elastic. ${ }^{19}$ Indeed, in this configuration, mobile firms are less inclined to agglomerate in the country offering a lower tax rate, because price competition among firms would be very fierce.

\subsection{Equilibrium versus optimum}

As we saw in the previous section, there is a prisoner's dilemma when trade costs lie in the interval $\left(\tau_{1}, \tau_{2}\right)$, as the Nash equilibrium of $D D$ generates less tax revenue for each country than they would get from setting uniform rates. Thus, if both countries were able to make a credible commitment to a coordinated switch of regimes, there would be a Pareto improvement. ${ }^{20}$ The problem is that neither country has an incentive to change to a uniform regime unilaterally. Indeed, both would have the incentive to defect from $U U$ should this configuration be established. We have further determined that whenever multiple Nash equilibria ( $U U$ and $D D$ ) exist, $U U$ Pareto dominates $D D$.

This result can be summarised in the following proposition and is illustrated in Figure 2.

Proposition 2. When trade costs are low $\left(\tau_{1}>\tau\right)$ or high $\left(\tau>\tau_{3}\right)$, tax-regime competition leads to socially optimal tax regimes, that yield the highest levels of total tax revenues. For an intermediate range of trade cost $\left(\tau_{3}>\tau>\tau_{1}\right)$, tax-regime competition results in discriminatory tax regimes while a uniform tax in each country would be socially preferable in generating higher tax revenues.

\footnotetext{
${ }^{19}$ See section 3.1

${ }^{20}$ Consumer surplus would be unaffected by such policy coordination (as each country would attract the same number of firms in equilibrium) so the only "losers" would be the foreign owners of capital.
} 
The prisoner's dilemma can be seen in zone 2 of Figure 2. $R^{D U}>R^{U U}$ and $R^{D D}>R^{U D}$ and so discriminating between firms on the basis of their mobility is a dominant strategy and consequently $D D$ is the unique Nash equilibrium. At the same time $R^{U U}>R^{D D}$ and a coordinated policy of uniform taxes would constitute a Pareto improvement.

Some comments are in order. First, contrary to Keen (2001), we show that tax preferences can reduce equilibrium revenues even though aggregate bases are independent of tax rates. Indeed, according to Janeba and Smart (2003), the result where tax discrimination leads to highest levels of tax revenues does not hold when when aggregate tax bases are elastic. Our result suggests that the desirability of tax discrimination is not exclusively related to the assumption of a fixed aggregate tax base. Haupt and Peters (2005) obtain a similar conclusion by introducing a home bias in the framework developed by Keen (2001). In contrast, our explanation lies in the fact that the location of mobile tax base is not only driven by differences in tax rates but also by other parameters of the economy. When the share of mobile tax base in the economy is large or trade costs are relatively high, the mobile tax base elasticity is low such that uniform tax policies lead to higher total tax revenues compared to tax discrimination policies.

Second, contrary to Haupt and Peters (2005), our analysis reveals that tax discrimination can be the outcome of a prisoner's dilemma game. As in Janeba and Peters (1999), when governments compete in tax principles, each country has a weak preference for tax discrimination. This result arises from the fact that the incentive for a government to discriminate is high when non-preferential tax regime prevails in each country. Indeed, all mobile bases always locate in the low-tax country. Each government has an incentive to undercut any positive tax imposed by the other government in order to accommodate all mobile bases. Hence, in Janeba and Peters (1999), countries apply a discriminatory tax policy at the Nash equilibrium. It is not surprising that this outcome is suboptimal since tax rates on mobile bases are null. With our framework, we consider other location factors due to the introduction of imperfect competition and trade costs so that tax rates on mobile firms are positive and all mobile bases do not locate in the low-tax country. 


\section{SUMMARY}

Trade integration and the increasing mobility of firms have raised the need for international coordination in tax systems, as suggested by different reports of the European Commission and OECD. The desirability of discriminatory tax regimes has received much attention from policy makers. The OECD and the European Union reported that giving such preferentially advantageous tax treatment to non-residents could be harmful. However, the gain from a uniform policy is not clear. Indeed, a transition from a uniform tax policy to a discriminatory regime implies a higher tax on the relatively immobile base and a fall in taxes on the more mobile base. As a result, a uniform tax policy enables governments to raise revenues from more mobile tax bases while revenues from more immobile bases increase when discriminatory regimes are applied.

In this paper, we have shown that countries will adopt uniform taxes when trade costs are high. Trade integration makes imposing the same tax on all firms less appealing such that, at low trade costs, the unique Nash equilibrium is characterized by governments discriminating against immobile firms. At some (intermediate) trade costs, such a policy outcome can arise in equilibrium yet will be inferior to both countries imposing the same tax on both immobile and footloose firms.

\section{REFERENCES}

Andersson F. and R. Forslid (2003). Tax competition and economic geography. Journal of Public Economic Theory 5, 279-303.

Baldwin R. and P. Krugman (2004). Agglomeration, integration and tax harmonization. European Economic Review 48(1), 1-23.

Brander J. A. and P. Krugman (1983). A 'reciprocal dumping' model of international trade. Journal of International Economics 15, 313-323.

Charlton A. (2003) Incentive bidding for mobile investment: Economic consequences and potential responses. OECD Working Paper n 2003.

Devereux, M., R. Griffith and A. Klemm (2002), Corporate income tax reforms and international tax competition. Economic Policy 35, 451-495. 
European Commission (1997). Towards tax co-ordination in the European Union: a package to tackle harmful tax competition. Communication from the European Commission to the council.

Gaigné C. and S. Riou (2007). Globalization, asymmetric tax competition and fiscal equalization, Journal of Public Economic Theory 9(5), 901-925.

Haufler A. and I. Wooton (2010). Competition for firms in an oligopolistic industry: The impact of economic integration, Journal of International Economics 80(2), 239-248.

Haupt A. and W. Peters (2005). Restricting preferential tax regimes to avoid harmful tax competition, Regional Science and Urban Economics 35(5), 493-507.

Head K. and T. Mayer (2004). The empirics of agglomeration and trade. In Handbook of Regional and Urban Economics, vol. 4, J.V. Henderson and J.-F. Thisse (eds), North-Holland, 2609-2669.

Janeba E. and W. Peters (1999). Tax evasion, tax competition and the gains from non-discrimination: The case of interest taxation in Europe, Economic Journal 109, 93-101.

Janeba E. and M. Smart (2003). Is targeted tax competition less harmful than its remedies? International Tax and Public Finance 10, 259-280.

Keen M. (2001). Preferential regimes can make tax competition less harmful. National Tax Journal $54,757-762$.

Kind H. J., K. H. Midelfart Knarvik and G. Schjelderup (2000). Competing for capital in a 'lumpy' world. Journal of Public Economics 78, 253-274.

Krugman P. (1991). Increasing returns and economic geography. Journal of Political Economy 99, 483-499.

Ludema R. and I. Wooton (1999). Regional integration, trade, and migration: are demand linkages relevant in Europe?" In R. Faini, J. De Melo and K. F. Zimmerman, eds., Migration: The Controversies and The Evidence, Cambridge, UK: Cambridge University Press, 51-68.

Ludema R. and I. Wooton (2000). Economic geography and the fiscal effects of regional integration. Journal of International Economics 52, 331-357.

Organization for Economic Cooperation and Development (1998). Harmful Tax Competition: An Emerging Global Issue, Paris: OECD. 
Organization for Economic Cooperation and Development (2000). Harmful tax competition: Progress in identifying and eliminating harmful tax practices, Report to the Ministers and Recommendations of the Committee on Fiscal Affairs

Organization for Economic Cooperation and Development (2004). The OECD's project on harmful tax practices, Paris: OECD.

Organization for Economic Cooperation and Development (2010). Promoting transparency and exchange of information for tax purposes, Paris: OECD.

Ottaviano, G. and T. van Ypersele (2005) Market access and tax competition. Journal of International Economics 67, 25-46.

Wilson, J. (2005), Tax competition with and without preferential treatment of a highly mobile tax base, in The Challenges of Tax Reform in a Global Economy, edited by James Alm, Jorge Martinez-Vazquez, and Mark Rider, Springer. 
Table 1. Tax revenues corresponding to tax regimes

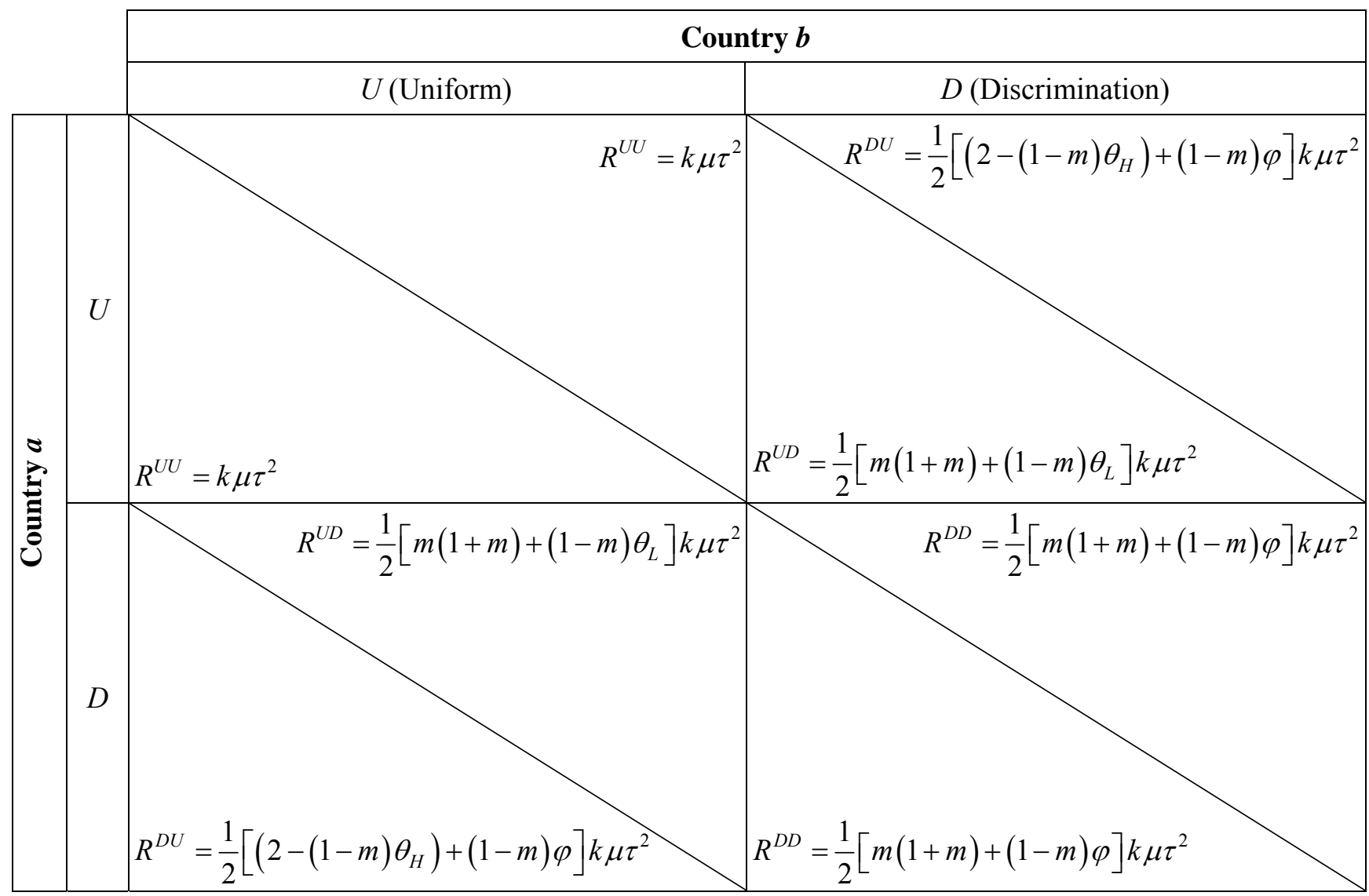




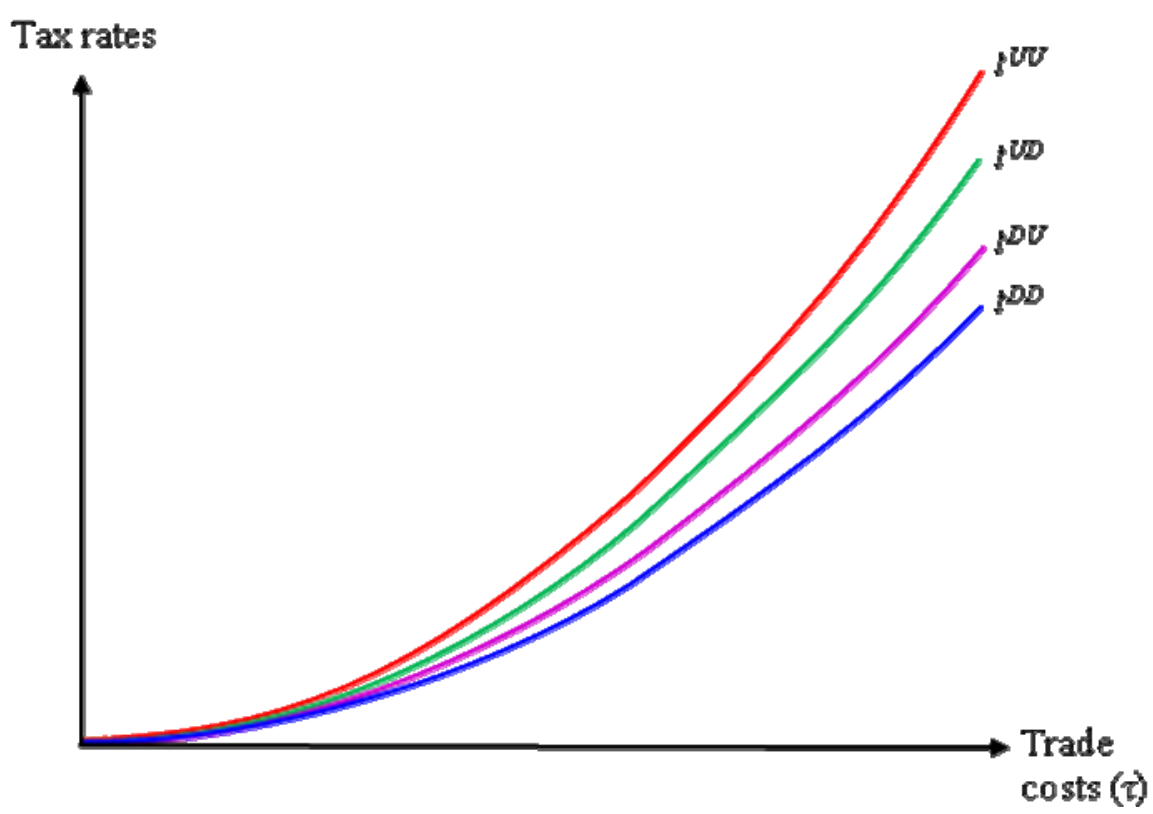

Figure 1. Trade integration and tax rates with respect to tax regime

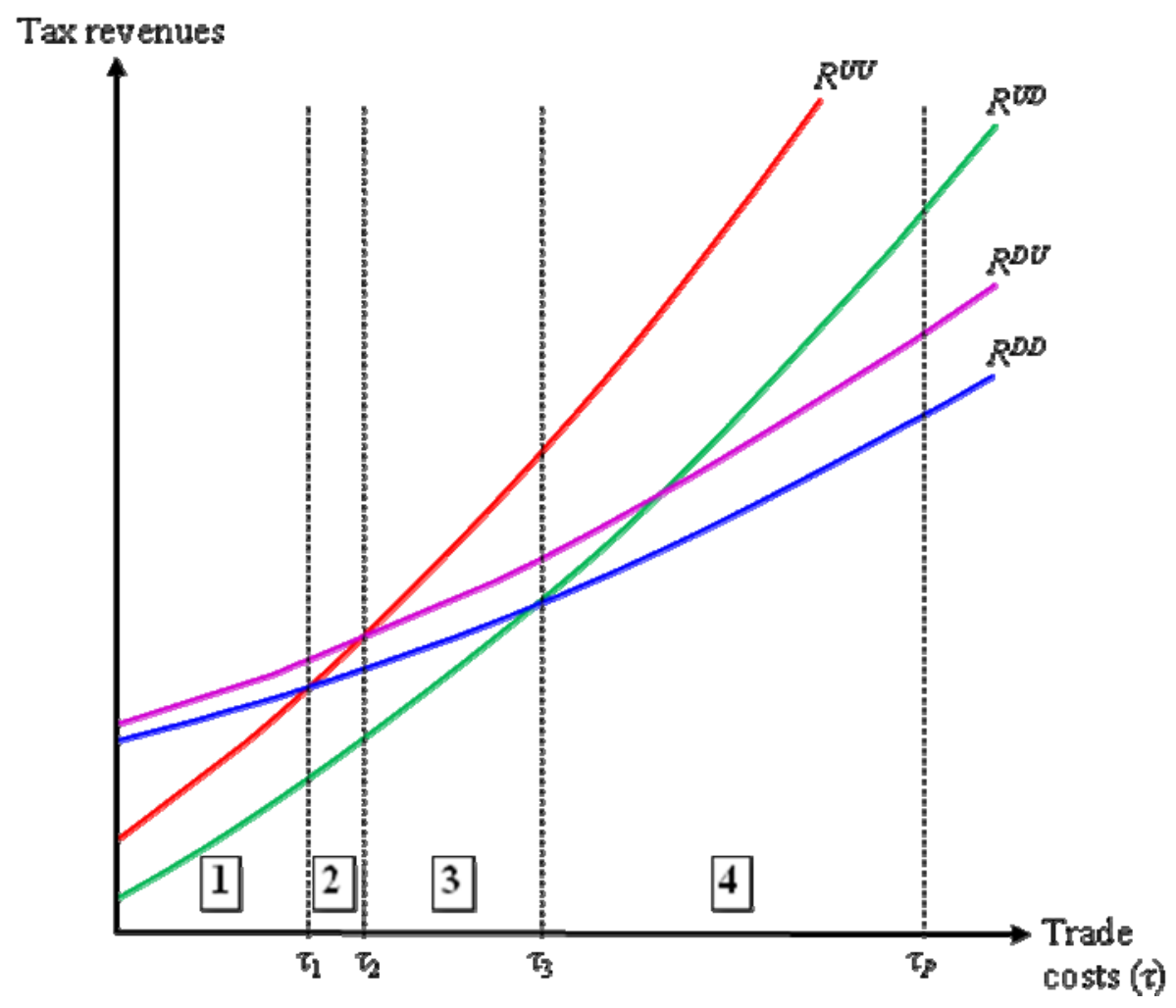

Figure 2. Trade integration and tax revenues with respect to tax regimes 